\title{
Frequency of Red Blood Cell Alloantibody in Kuwaiti Population
}

\author{
Reem Ameen ${ }^{\mathrm{a}}$ Ohood Al-Eyaadi ${ }^{\mathrm{b}}$ Salem Al-Shemmaric \\ Rafiqul Chowdhury ${ }^{d}$ Abdulaziz Al-Bashir ${ }^{b}$ \\ ${ }^{a}$ Department of Medical Laboratory Sciences, Faculty of Allied Health Sciences, Kuwait University; \\ ${ }^{b}$ Kuwait Central Blood Bank, Ministry of Health, ${ }^{\mathrm{c}}$ Department of Medicine, Faculty of Medicine, \\ Kuwait University, ${ }^{\mathrm{d}}$ Department of Health Information and Administration, Faculty of Allied Health and Nursing, \\ Kuwait University, Kuwait
}

\section{Key Words}

Red blood cells · Alloimmunization, frequency · Arabs · Kuwait

\begin{abstract}
Objective: The aim of this study was to analyze the alloimmunization against red blood cells (RBC) among Kuwaiti population. Materials and Methods: Retrospective analysis of RBC alloimmunization among 179,045 Kuwaiti patients, pregnant women, and allogeneic blood donors was conducted for the period of 1992-2001. The frequency of 24 alloantibody specificities from 1,278 alloimmunized Kuwaitis was estimated. Results: The prevalence of positive antibody screen in Kuwait was $0.49 \%$. The five most frequently identified alloantibodies were anti-D (27.3\%), anti-E (18.5\%), anti-K (15.6\%), anti-Le $(8.7 \%)$, and anti-Le $\mathrm{b}^{\mathrm{b}}(6.6 \%)$. Frequency of alloimmunization was greater among Kuwaiti female than male patients (3.2 F to $1 \mathrm{M})$. Anti-D ( $p<0.001)$, anti-E ( $p=0.05)$, anti-K ( $p=0.04$ ) were also more frequently identified alloantibody among Kuwaiti females. Conclusion: The results show higher predominance of RBC alloimmunization in females than males. Anti-D, anti-E, and anti-K were the most common clinically significant alloantibodies identified in the Kuwaiti population and were also more frequent among Kuwaiti females.
\end{abstract}

Copyright (c) 2005 S. Karger AG, Basel
(C) $2005 \mathrm{~S}$. Karger AG, Basel

1011-7571/05/0144-0230\$22.00/0

Fax +4161306 1234

E-Mail karger@karger.ch

www.karger.com
Accessible online at: www.karger.com/mpp

\section{Introduction}

The incidence of red blood cell (RBC) alloimmunization depends on the demography of the population being studied. Previous studies of the frequency of RBC alloimmunization have focused on Western societies [1-4]. Reports on the frequency of RBC alloimmunized patients or allogeneic blood donors are limited in populations from the Arabian Gulf region.

The state of Kuwait is located at the northeast extremity of the Arabian Peninsula with a total population of 2.2 million in 2001. Kuwaitis comprised $38 \%$ of all residents, consisting of $18.8 \%$ males and $19.3 \%$ females. Non-Kuwaitis comprised the remaining $62 \%$ with higher predominance of males (42\%) compared to females (20\%) [5]. The main reason for the large percentage of non-nationals in the country is due to immigrant workers from many different countries [6], some of whom are accompanied by their family.

The Kuwaiti national population is genetically homogeneous because of the high rate of consanguinity [7]. Hence the Kuwaiti population is ideal for studying RBC alloimmunization. Virtually, all RBC alloantibody identifications are performed at the Kuwait Central Blood Bank, as it is the only referral center and local supplier of blood and blood components in Kuwait. Equally, a centralized system of RBC alloantibody records is available,

Dr. Reem Ameen

PO Box 34020

73251 Audiliah (Kuwait)

Tel. +965 7887588, Fax +965 2563877, E-Mail reemameen@hotmail.com 
and thus provides an opportunity to evaluate the frequency of alloimmunization to RBC antigens.

This retrospective study sets out to evaluate the frequency of alloimmunization to $\mathrm{RBC}$ antigens in the $\mathrm{Ku}$ waiti population.

\section{Subjects and Methods}

\section{Subjects and Samples}

The data set included 179,045 Kuwaiti patients, pregnant women, and allogeneic blood donors who underwent antibody screening between 1992 and 2001. Each alloimmunized subject record was unique, and no subject was entered twice. Although some patients or pregnant women might have multiple antibody investigations only one was entered into the database. AB0, Rh typing, and gender were available for alloimmunized Kuwaitis. The alloimmunized subjects were divided into the following subgroups: patients, pregnant women, and allogeneic blood donors.

\section{Serology Test}

Antibody screening was performed as a routine immunohematologic investigation in support of the transfusion service. A standard two-cell panel (Immucor, Calif., USA, and Ortho, N.J., USA) was used to screen for RBC alloantibodies using tube test method. A low ionic strength solution was used for indirect antiglobulin method (Gamma Biological Inc., Houston, Tex., USA). A mixture of two parts serum, one part RBCs, and two parts low ionic strength solution was incubated for $15 \mathrm{~min}$ at $37^{\circ} \mathrm{C}$. The cells were then washed 3 times in phosphate-buffered saline (Inverclyde Biological, Scotland, UK), and polyspecific anti-human globulin serum (Gamma Biological Inc, Houston, Tex., USA) was then added before spinning and final reading. Any pretransfusion sera that had a positive antibody screen were investigated to identify the specificity of the alloantibody. Antibody specificity was determined by using a commercial RBC panel tested against the patient's serum in the same phases as antibody screening, including enzyme (ficin) treatment (Ortho, N.J., USA, and Gamma Biologicals Inc., Houston, Tex., USA). The criteria for antibody specificity were based on American Association of Blood Banks recommendations [8]. In case of difficulty in identifying RBC alloantibody locally, the patient samples were referred to the International Blood Group Reference Laboratory (IBGRL) at Bristol, United Kingdom, for further investigations. Nine such samples were referred to IBGRL for serologic investigations.

\section{Statistical Analysis}

The frequency of each alloantibody was assessed based on the study population, as well as gender. Fisher's exact test was performed to determine the difference in antibody distribution by gender; $p$ value $\leq 0.05$ was considered significant. The analyses were performed using SPSS software version 10.5.

\section{Results}

The 179,045 subjects were divided as follows: 5,916 patients (without inclusion of pregnant women), 2,932 pregnant women, and 170,197 allogeneic blood donors. Of the screened subjects, $1,278(0.7 \%)$ had alloantibodies with clinical significance: $836(65.4 \%)$ patients, 412 (32.2\%) pregnant women, and $30(2.3 \%)$ donors (table 1$)$. The prevalence of alloimmunization among Kuwaiti blood recipients and donors (without the inclusion of pregnant women) was $0.49 \%$ (210 male, 1,068 female). Among the patient group there were 201 men and 635 women, while among the donor group there were 9 men and 21 women.

Twenty-four of the RBC alloantibody specificities were identified (table 1). In general, the five most frequently identified alloantibodies were anti-D (27.3\%), anti-E (18.5\%), anti-K (15.6\%), anti-Le ${ }^{\mathrm{a}}(8.7 \%)$, and anti$\operatorname{Le}^{\mathrm{b}}(6.6 \%)$.

A total of $72.6 \%$ of the study population had one alloantibody, 22.2\% two alloantibodies, 3\% three alloantibodies, $2.1 \%$ had between four and six alloantibodies.

The frequency of developing of RBC alloantibody was higher among Kuwaiti females than males in patients and allogeneic blood donors. Antibodies to D, E and $\mathrm{K}$ were more frequent among females with positive antibody screen. Anti-D was identified in the sera of $177(90.3 \%)$ alloimmunized women compared to only $19(9.7 \%)$ men who formed anti-D. Anti-E was identified in the sera of $123(75 \%)$ alloimmunized women compared to only 41 (25\%) males. Anti-K was present in the sera of $109(70.3 \%)$ females, compared to $46(29.6 \%)$ males (tables 1, 2). However, the remaining clinically insignificant alloantibodies such as anti-Le ${ }^{\mathrm{a}}$ and anti-Le ${ }^{\mathrm{b}}$ showed no gender difference (data not shown).

Alloantibodies against high frequency antigens (HFA) were identified in 6 subjects of whom 2 had anti-Ge ${ }^{2}, 1$ had anti-Lan, and 3 unidentified antibody against HFA.

\section{Discussion}

The incidence of alloimmunization against RBC antigen depends on the demography of the population being studied. Characteristics such as race and sex of the individual and the population being studied (patients, obstetric patient, and allogeneic blood donor) make it difficult to relate the experience of one study to another. Most of the previously described data $[2,3,9,10]$ are related to Western society, and/or a particular transfusion indica- 
Table 1. Total RBC alloantibody identified frequency in Kuwaitis from 1992 to 2001

\begin{tabular}{|c|c|c|c|c|c|}
\hline \multirow{2}{*}{$\begin{array}{l}\text { Antigen } \\
\text { system or } \\
\text { collection }\end{array}$} & \multirow[t]{2}{*}{ Antigen } & \multicolumn{3}{|c|}{ RBC alloantibodies identified } & \multirow{2}{*}{$\begin{array}{l}\text { Total of all } \\
\text { subjects with } \\
\text { alloantibody } \\
(\mathrm{n}=1,278)\end{array}$} \\
\hline & & $\begin{array}{l}\text { patients } \\
(\mathrm{n}=836,65.4 \%)\end{array}$ & $\begin{array}{l}\text { pregnant women } \\
(\mathrm{n}=412,32.2 \%)\end{array}$ & $\begin{array}{l}\text { donors } \\
(\mathrm{n}=30,2.3 \%)\end{array}$ & \\
\hline \multirow[t]{7}{*}{$\mathrm{Rh}$} & $\mathrm{D}$ & $188(22.5 \%)$ & $153(37 \%)$ & $8(26.7 \%)$ & $349(27.3 \%)$ \\
\hline & $\mathrm{C}$ & $38(4.3 \%)$ & $20(4.9 \%)$ & - & $58(4.5 \%)$ \\
\hline & $\mathrm{c}$ & $33(4 \%)$ & $26(6.3 \%)$ & $2(6.7 \%)$ & $61(4.8 \%)$ \\
\hline & $\mathrm{E}$ & $159(19 \%)$ & $72(17.5 \%)$ & $5(16.7 \%)$ & $236(18.5 \%)$ \\
\hline & $\mathrm{e}$ & $9(1.1 \%)$ & $5(1.2 \%)$ & - & $14(1.1 \%)$ \\
\hline & $\mathrm{C}^{\mathrm{w}}$ & $5(0.6 \%)$ & $3(0.7 \%)$ & - & $8(0.6 \%)$ \\
\hline & V & $15(1.8 \%)$ & $4(1 \%)$ & - & $19(1.5 \%)$ \\
\hline \multirow[t]{3}{*}{ Kell } & $\mathrm{K}$ & $154(18.3 \%)$ & $45(11 \%)$ & $1(3.3 \%)$ & $200(15.6 \%)$ \\
\hline & $\mathrm{Kp}^{\mathrm{a}}$ & $4(0.5 \%)$ & - & - & $4(0.3 \%)$ \\
\hline & $\mathrm{JS}^{\mathrm{a}}$ & $4(0.5 \%)$ & - & - & $4(0.3 \%)$ \\
\hline \multirow[t]{2}{*}{ Duffy } & $\mathrm{Fy}^{\mathrm{a}}$ & $21(2.5 \%)$ & $8(2.0 \%)$ & - & $29(2.3 \%)$ \\
\hline & $\mathrm{Fy}^{\mathrm{b}}$ & $4(0.5 \%)$ & $1(0.2 \%)$ & - & $5(0.4 \%)$ \\
\hline \multirow[t]{2}{*}{ Kidd } & $\mathrm{Jk}^{\mathrm{a}}$ & $18(2.1 \%)$ & $7(1.7 \%)$ & - & $25(2.0 \%)$ \\
\hline & $\mathrm{Jk}^{\mathrm{b}}$ & $9(1.1 \%)$ & $5(1.2 \%)$ & - & $14(1.1 \%)$ \\
\hline \multirow[t]{2}{*}{ Lewis } & $\mathrm{Le}^{\mathrm{a}}$ & $62(7.4 \%)$ & $46(11.2 \%)$ & $3(10 \%)$ & $111(8.7 \%)$ \\
\hline & $\mathrm{Le}^{\mathrm{b}}$ & $49(5.8 \%)$ & $31(7.6 \%)$ & $4(13 \%)$ & $84(6.6 \%)$ \\
\hline $\mathrm{P}$ & $\mathrm{P} 1$ & $35(4.2 \%)$ & $21(5.1 \%)$ & $3(10 \%)$ & $59(4.6 \%)$ \\
\hline \multirow[t]{2}{*}{ Luthern } & $\mathrm{Lu}^{\mathrm{a}}$ & $3(0.4 \%)$ & $1(0.2 \%)$ & - & $4(0.3 \%)$ \\
\hline & $\mathrm{Lu}^{\mathrm{b}}$ & $2(0.2 \%)$ & - & - & $2(0.2 \%)$ \\
\hline \multirow[t]{4}{*}{ MNSs } & $\mathrm{M}$ & $13(1.5 \%)$ & $4(1.0 \%)$ & - & $17(1.3 \%)$ \\
\hline & $\mathrm{N}$ & $3(0.4 \%)$ & $1(0.2 \%)$ & - & $4(0.3 \%)$ \\
\hline & $\mathrm{S}$ & $7(0.8 \%)$ & $6(1.5 \%)$ & $3(10 \%)$ & $14(1.1 \%)$ \\
\hline & $\mathrm{S}$ & - & $3(0.7 \%)$ & - & $3(0.2 \%)$ \\
\hline HFA & HFA & $2(0.2 \%)$ & - & $1(3.3 \%)$ & $3(0.2 \%)$ \\
\hline
\end{tabular}

Total number of alloimmunized patients 1,278, total number of alloantibodies 1,329. Antibodies against high frequency antigens (HFA) identified were anti-Lan and anti$\mathrm{Ge}^{2}$.
Table 2. Sex distribution of the three most common clinically significant alloantibodies among Kuwaiti patients and donors

\begin{tabular}{llll}
\hline Alloantibody & Male & Female & p value \\
\hline D & $19(9.7 \%)$ & $177(90.3 \%)$ & $<0.001^{*}$ \\
E & $41(25 \%)$ & $123(75 \%)$ & $0.05^{*}$ \\
K & $46(29.6 \%)$ & $109(70.3 \%)$ & $0.04^{*}$ \\
\hline Total & 106 & 409 & \\
\hline
\end{tabular}

tion such as sickle cell disease [11]. However, little information is available regarding the alloimmunization among Arabs from the Arabian Gulf region. Furthermore, most of the previously mentioned studies did not include antibodies that react at room temperature (RT) because they are considered clinically insignificant. However, these RT reactive antibodies do interfere with the pretransfusion laboratory investigations, and their presence should be considered in determining the incidence of positive antibody screening within a population [4]. Alloantibodies that react at RT were included in the current study.

The overall incidence of alloimmunization among transfusion recipients and blood donors (without the inclusion of pregnant women) was $0.49 \%$ in this study, which was lower than previously reported, $0.8-1.6 \%$ among transfusion recipients and $0.32-0.89 \%$ among donors $[3,4,12]$.

In this study, the incidence of alloimmunization among female patients and donors was more than 3 times higher than among male subjects. Several reports have shown that the male:female ratio ranges from 1:2 to $1: 2.7$ [3, 4, $10,12,13]$. Several possible reasons may account for the high female predominance observed in our study. First the fertility rate in Kuwait is higher than in Western societies; the estimated fertility rate among Kuwaiti women 
is 4.2 [14]. Therefore, immunization through pregnancy $[10,12]$ could be the main reason for the greater incidence of RBC alloimmunization among Kuwaiti females. Second, it is known that postpartum administration of anti-D immunoglobulin is expected to significantly lower the percentage of developing anti-D among Rh-D-negative pregnant women [15]. However, administration of anti-D immunoglobulin may not prevent immunization if the quantity of D-positive fetal red cells in the mother's circulation exceeds the immunosuppressive capacity of anti-D immunoglobulin. Historically, Kleihauer acid elution test, which detects fetal hemoglobin $(\mathrm{HbF})$, has been used to estimate the volume of fetal red cells that have entered the mother's circulation. Unfortunately, in Kuwait the majority of the hospitals do not routinely use the Kleihauer test or any other alternative technique to quantify the amount of fetomaternal hemorrhage (FMH). Most of women usually receive only a single postnatal dose $(1,500 \mathrm{IU}$ or $300 \mu \mathrm{g})$ of anti-D immunoglobulin without prior assessment of FMH. Furthermore, anti-D immunoglobulin prophylaxis is not usually administrated as a routine antenatal prophylaxis to Rh-D-negative women, that in addition to the lack of proper intervention in some of the cases following potential sensitization events such as abortion, ectopic pregnancy, transfusion of blood products. That could have particularly influenced the incidence of developing anti-D observed in all of the subgroups in the current study. Most of the previously published reports in Western societies have shown a decline in the frequency of developing anti-D combined with the increase of the prevalence of anti-K and anti-E since the introduction of anti-D immunoglobulin $[1,3,4$, $9,10,16]$. The differences observed in this study compared to other published reports further support the importance of adequate assessment of the amount FMH and therefore adequate dosage of anti-D immunoglobulin. National policy to screen the sera of Kuwaiti pregnant women for AB0, Rh, and antibody screen is currently underway. The main objectives of this policy are to identify pregnancy cases at risk of developing hemolytic disease of the newborn, and more importantly to identify Rh-Dnegative women who need anti-D immunoglobulin prophylaxis.

This study also showed that anti-E was the second most common specificity among Kuwaiti females, followed by anti-K. Currently no policy exists that fertile women should receive AB0, Rh-compatible, and Kellnegative blood at the government or private hospitals. This could explain the obvious sex difference associated with anti-E and anti-K.
Most of the previously mentioned studies that described the high female predominance have included pregnant women (with the exception of Blumberg et al. [13]), while those studies that included transfused patients only found no difference between the genders. In our study, the alloimmunization rate among female patients was more than 3 times higher than male (3.2:1). This further suggests the great incidence of alloimmunization among Kuwaiti females compared to males. Further, RBC phenotypic study is currently performed on Kuwaiti blood donors in order to identify the RBC antigenic profile among the Kuwait population.

\section{Conclusion}

The results show higher predominance of $\mathrm{RBC}$ alloimmunization in females than males. Anti-D, anti-E, and anti-K were the most common clinically significant alloantibody identified in the Kuwaiti population and were also more frequent among Kuwaiti females.

\section{Acknowledgments}

We are thankful to the Immunohematology Laboratory staff at the Kuwait Central Blood Bank. We are also thankful to the International Blood Group Reference Laboratory (Bristol, United Kingdom) for their continued support and collaborations. 


\section{References}

1 Fluit CR, Kunst VA, Drenthe-Schonk AM: Incidence of red cell antibodies after multiple blood transfusion. Transfusion 1990;30:532535.

-2 Redman M, Regan F, Contreras M: A prospective study of the incidence of red cell alloimmunization following transfusion. Vox Sang 1996;71:216-220.

-3 Walker RH, Lin DT, Hartrick MB: Alloimmunization following blood transfusion. Arch Pathol Lab Med 1989;113:254-261.

$\checkmark 4$ Winters JL, Pinedo AA, Gorden LD, et al: RBC alloantibody specificity and antigen potency in Olmsted County, Minnesota. Transfusion 2001;41:1413-1420.

5 Public Authority for Civil Information (PACI): Directory of Civil Information: Regulation and Labor Force 2001, Kuwait.

-6 Shah NM, Shah MA: Socioeconomic and health care determinants of child survival in Kuwait. J Biosoc Sci 1990;22:239-253.
7 Radovanovic A, Shah N, Behbehani J: Prevalence and social correlates of consanguinity in Kuwait. Ann Saudi Med1999;19:206-210.

8 Vengelen Tyler V, et al: Technical Manual, ed 12. American Association of Blood Bank, 1996.

$\checkmark 9$ Hoeltge GA, Domen RE, Rybicki LA, Schaffer PA: Multiple red cell transfusion and alloimmunization: Experience with 6,996 antibodies detected in a total of 159,262 patients from 1985 to 1993. Arch Pathol Lab Med 1995;119:42-45.

10 Spielmann W, Seidl S: Prevalence of irregular red cell antibodies and their significance in blood transfusion and antenatal care. Vox Sang1974;26:551-559.

11 Moreira G, Bordin J, Kuroda A, Kerbauy J: Red blood cell alloimmunization in sickle cell disease: The influence of racial and antigenic pattern differences between donors and recipients in Brazil. Am J Hematol 1996;52:197200.
12 Giblett ER: Blood group alloantibodies: An assessment of some laboratory practices. Transfusion 1977;71:266-274.

13 Blumberg N, Ross K, Avila E, Peck K: Should chronic transfusion be matched for antigens other than $\mathrm{ABO}$ and $\mathrm{Rh}_{0}$ (D)? Vox Sang 1984;47:205-208.

14 Health and Vital Statistics Division: Vital Health and Statistics Abstract. Kuwait Health. Kuwait, Department of Medical Records and Statistics Ministry of Health, 1999, p 43.

15 Lee D, Contreras M, Robson S, Rodeck C, Whittle M: Recommendations for the use of anti-D immunoglobulin for $\mathrm{Rh}$ prophylaxis. Transfus Med 1999;9:93-97.

-16 Brantley SG, Ramsey G: Red cell alloimmunization in multi-transfused HLA typed patients. Transfusion 1988;28:463-466. 